\title{
DNA Damage in Inflammation-Related Carcinogenesis and Cancer Stem Cells
}

\author{
Shiho Ohnishi, ${ }^{1}$ Ning Ma, ${ }^{2}$ Raynoo Thanan,, ${ }^{3,4}$ Somchai Pinlaor, ${ }^{4,5}$ Olfat Hammam, \\ Mariko Murata, ${ }^{7}$ and Shosuke Kawanishi ${ }^{1}$ \\ ${ }^{1}$ Faculty of Pharmaceutical Sciences, Suzuka University of Medical Science, Suzuka 513-8670, Mie, Japan \\ ${ }^{2}$ Faculty of Health Science, Suzuka University of Medical Science, Suzuka 510-0293, Mie, Japan \\ ${ }^{3}$ Department of Biochemistry, Faculty of Medicine, Khon Kaen University, Khon Kaen 40002, Thailand \\ ${ }^{4}$ Department of Parasitology, Faculty of Medicine, Khon Kaen University, Khon Kaen 40002, Thailand \\ ${ }^{5}$ Liver Fluke and Cholangiocarcinoma Research Center, Faculty of Medicine, Khon Kaen University, Khon Kaen 40002, Thailand \\ ${ }^{6}$ Departments of Pathology and Urology, Theodor Bilharz Research Institute, Giza 12411, Egypt \\ ${ }^{7}$ Department of Environmental and Molecular Medicine, Mie University Graduate School of Medicine, Tsu 514-8507, Mie, Japan
}

Correspondence should be addressed to Shosuke Kawanishi; kawanisi@suzuka-u.ac.jp

Received 2 August 2013; Accepted 20 September 2013

Academic Editor: Pavel Rossner Jr.

Copyright (C) 2013 Shiho Ohnishi et al. This is an open access article distributed under the Creative Commons Attribution License, which permits unrestricted use, distribution, and reproduction in any medium, provided the original work is properly cited.

Infection and chronic inflammation have been recognized as important factors for carcinogenesis. Under inflammatory conditions, reactive oxygen species (ROS) and reactive nitrogen species (RNS) are generated from inflammatory and epithelial cells and result in oxidative and nitrative DNA damage, such as 8-oxo-7,8-dihydro-2' -deoxyguanosine (8-oxodG) and 8-nitroguanine. The DNA damage can cause mutations and has been implicated in the initiation and/or promotion of inflammation-mediated carcinogenesis. It has been estimated that various infectious agents are carcinogenic to humans (IARC group 1), including parasites (Schistosoma haematobium (SH) and Opisthorchis viverrini (OV)), viruses (hepatitis C virus (HCV), human papillomavirus (HPV), and EpsteinBarr virus (EBV)), and bacterium Helicobacter pylori (HP). SH, OV, HCV, HPV, EBV, and HP are important risk factors for bladder cancer, cholangiocarcinoma, hepatocellular carcinoma, cervical cancer, nasopharyngeal carcinoma, and gastric cancer, respectively. We demonstrated that 8-nitroguanine was strongly formed via inducible nitric oxide synthase (iNOS) expression at these cancer sites of patients. Moreover, 8-nitroguanine was formed in Oct3/4-positive stem cells in SH-associated bladder cancer tissues and in Oct3/4- and CD133-positive stem cells in OV-associated cholangiocarcinoma tissues. Therefore, it is considered that oxidative and nitrative DNA damage in stem cells may play a key role in inflammation-related carcinogenesis.

\section{DNA Damage in Inflammation-Related Carcinogenesis}

Infection and chronic inflammation have been recognized as important risk factors for carcinogenesis and malignancies [1-3]. The International Agency for Research on Cancer (IARC) has estimated that approximately $18 \%$ of cancer cases worldwide are attributable to infectious diseases caused by bacteria, viruses, and parasites [4]. The burden of cancer caused by infectious agents is shown in Table 1. Inflammation can be induced not only by chronic infection, but also by many other physical, chemical, and immunological factors $[5,6]$. It has been estimated that chronic inflammation accounts for approximately $25 \%$ of human cancers.

Under inflammatory conditions, reactive oxygen species (ROS) and reactive nitrogen species (RNS) are generated from inflammatory and epithelial cells [7]. ROS and RNS are capable of causing damage to various cellular constituents, such as nucleic acids, proteins, and lipids. ROS are generated from multiple sources, including inflammatory cells, carcinogenic chemicals and their metabolites, and the electron transport chain in mitochondria $[2,3]$. ROS can induce the formation of oxidative DNA lesion products, including 8-oxo-7,8-dihydro- $2^{\prime}$-deoxyguanosine (8-oxodG), which is considered to be mutagenic $[7,8]$. During DNA synthesis, 
TABLE 1: Possible markers for cancer stem cells in inflammation-related cancer.

\begin{tabular}{|c|c|c|c|c|}
\hline \multicolumn{2}{|c|}{$\begin{array}{l}\text { Etiologic agent/ } \\
\text { pathologic condition }\end{array}$} & Associated cancer & $\begin{array}{l}\text { Detection of } \\
\text { 8-nitroguanine }\end{array}$ & $\begin{array}{l}\text { Possible markers for cancer stem } \\
\text { cells related to each cause } \\
\text { [references] }\end{array}$ \\
\hline \multirow[t]{4}{*}{ Parasites } & SH & Bladder cancer & Patients $[10,11]$ & Oct3/4 (patients with SH) [10] \\
\hline & & & & CD44v6 (patients without SH) [11] \\
\hline & OV & Cholangiocarcinoma & Hamsters [12-15] & - \\
\hline & & & Patients $[16,17]$ & CD133, Oct3/4 [17] \\
\hline \multirow[t]{7}{*}{ Viruses } & $\mathrm{HCV}$ & Hepatocellular carcinoma & Patients with HCV [18] & CK19 [19] \\
\hline & $\mathrm{HBV}$ & & Mice with HBV [DN] & Nanog, CD133 [20] \\
\hline & $\mathrm{HPV}$ & Cervical carcinoma & Patients [21] & CK17 $[22,23]$ \\
\hline & & & & CD44 (HPV16) [24] \\
\hline & & & & Oct3/4 (HPV16) [25] \\
\hline & EBV & Nasopharyngeal carcinoma & Patients [26] & LMP2A ([27] and a lot) \\
\hline & & & & LMP1, Bmi-1 [28] \\
\hline \multirow[t]{3}{*}{ Bacteria } & $\mathrm{HP}$ & Gastric cancer & Patients $[29,30]$ & SALL4, KLF5 [31] \\
\hline & & & & KLF5 [32] \\
\hline & & & & LgR5 [33] \\
\hline \multirow[t]{6}{*}{$\begin{array}{l}\text { Inflammatory } \\
\text { diseases }\end{array}$} & IBD & Colorectal cancer & Mice [34] & - \\
\hline & LP & $\begin{array}{l}\text { Oral squamous cell } \\
\text { carcinoma }\end{array}$ & Patients [35] & Bmi-1 [36] \\
\hline & & & & KRT15 [37] \\
\hline & $\mathrm{BE}$ & $\begin{array}{l}\text { Barrett's esophageal } \\
\text { adenocarcinoma }\end{array}$ & Patients [38] & Oct3/4 [39] \\
\hline & & & & CD133 [40] \\
\hline & & & & Musashi-1 [41] \\
\hline Others & Asbestos & $\begin{array}{l}\text { Mesothelioma, lung } \\
\text { carcinoma }\end{array}$ & Mice [42] & - \\
\hline
\end{tabular}

SH: Schistosoma haematobium, OV: Opisthorchis viverrini, HCV: hepatitis C virus, HBV: hepatitis B virus, HPV: human papillomavirus, EBV: Epstein-Barr virus, HP: Helicobacter pylori, IBD: inflammatory bowel diseases, LP: lichen planus, BE: Barrett's esophagus, DN: data not shown.

adenine is misincorporated opposite 8-oxodG, leading to $\mathrm{G}: \mathrm{C}$ to T:A transversions [9].

Nitric oxide (NO) is synthesized by NO synthases. There are three isoforms: neuronal NO synthase (nNOS, also known as NOS1), inducible NO synthase (iNOS or NOS2), and endothelial NO synthase (eNOS or NOS3) [43, 44]. iNOS is activated to drastically generate NO in inflammatory and epithelial cells under inflammatory conditions, while eNOS and nNOS are constitutively expressed and produce relatively small amounts of NO. iNOS can be also upregulated by transcription factors such as NF- $\kappa \mathrm{B}, \mathrm{HIF1}-\alpha$, STAT, and TNF- $\alpha$. NF- $\kappa$ B plays a central role in inflammation through its ability to induce transcription of proinflammatory genes, including iNOS, and functions as a tumor promoter in inflammation-associated cancer [45].

Excess NO production plays a crucial role in an enormous variety of pathological processes, including cancer [43]. $\mathrm{NO}$ reacts with superoxide $\left(\mathrm{O}_{2}{ }^{--}\right)$to form peroxynitrite $\left(\mathrm{ONOO}^{-}\right)$, a highly reactive species causing 8-oxodG and 8nitroguanine $[46,47]$. The reaction of guanine with $\mathrm{ONOO}^{-}$ forms 8-nitroguanine as the major compound [46], while adenine nitration is minor compared to its C8-oxidation [48]. Akaike et al. have demonstrated that 8-nitroguanine is formed via NO production associated with inflammation in mice with viral pneumonia [49]. 8-Nitroguanine is considered to be not only a marker of inflammation, but also a potential mutagenic DNA lesion, leading to carcinogenesis [50]. 8-Nitroguanine formed in DNA is chemically unstable and thus can be spontaneously released, resulting in the formation of an apurinic site [51]. The apurinic site can form a pair with adenine during DNA synthesis, leading to G:C to T:A transversions [52]. However, the discovery of translesion DNA polymerases and their role in the mutagenesis in living cells made this paradigm rather obsolete [53, 54]. AP sites are indeed mutagenic, but the A-rule does not really describe its mutagenic potential. Cells deficient in Rev1 and Rev3, subunits of DNA polymerase $\zeta$, were hypersensitive to nitrative stress, and translesion DNA synthesis past apurinic sites mediated by this polymerase might contribute to extensive point mutations [55]. It has been reported that adenine is preferentially incorporated opposite 8-nitroguanine during DNA synthesis catalyzed by polymerase $\eta$ and $\kappa \Delta \mathrm{C}$ in 
a cell-free system, suggesting that G:C to T:A transversions can occur [56]. In the $\mathrm{ONOO}^{-}$-treated supF shuttle vector, which was replicated in host Escherichia coli cells, the majority of mutations occurred at G:C base pairs, predominantly involving G:C to T:A transversions [57]. Thus, 8-nitroguanine is a potentially mutagenic DNA lesion that can participate in initiation and promotion in infection-related carcinogenesis.

We have investigated the formation of 8-nitroguanine and 8-oxodG in various clinical specimens and animal models in relation to inflammation-related carcinogenesis, as summarized in Table 1. It is noteworthy that DNA damage was specifically induced at sites of carcinogenesis under chronic infection and various inflammatory conditions, as reviewed previously $[2,3]$. It has been estimated that 11 infectious agents are carcinogenic to humans (Group 1) by IARC: parasites (Schistosoma haematobium (SH), Opisthorchis viverrini (OV), and Clonorchis sinensis (CS)), viruses (hepatitis $\mathrm{B}$ and $\mathrm{C}$ virus (HBV, and $\mathrm{HCV}$ ), human papillomavirus (HPV), Epstein-Barr virus (EBV), human T-cell lymphotropic virus (HTLV-1), Kaposi's sarcoma herpesvirus (KSHV), and human immunodeficiency virus-1 (HIV-1)), and bacterium Helicobacter pylori (HP) $[4,58]$. We demonstrated that 8-nitroguanine was strongly formed via iNOS expression at related cancer sites of $\mathrm{SH}, \mathrm{OV}, \mathrm{HBV}, \mathrm{HCV}, \mathrm{HPV}, \mathrm{EBV}$, and HP $[2,3,10,11]$. The IARC classification of CS has been recently updated from $2 \mathrm{~A}$ to 1 , so we have not yet collected enough data for 8-nitroguanine. The mechanism of carcinogenesis by HTLV-1, KSHV, or HIV-1 seems not to be associative to inflammation. We could not observe 8nitroguanine in leukaemia samples from patients infected with HTLV-1 (data not shown). 8-Nitroguanine was also formed in tissues from patients with inflammatory diseases, such as inflammatory bowel diseases (IBD), Lichen planus (LP), and Barrett's esophagus (BE) $[3,38]$. Recently, we have reported that the formation of 8-nitroguanine and 8 -oxodG increased significantly in the order of Barrett's esophageal adenocarcinoma $>$ Barrett's esophagus $>$ normal tissues. Treatment of BE patients with proton pump inhibitors (PPIs), which is expected to reduce the risk of Barrett's esophageal adenocarcinoma, suppressed these DNA lesions probably via activation of an antioxidant enzyme Mn-SOD [38]. Regarding inflammation-related carcinogenesis without infection, we describe the formation of 8-nitroguanine in lung tissues of mice intratracheally administered asbestos [42], although the precise mechanism of nitrative DNA damage remains to be clarified. Nitrative stress is involved in the asbestos-derived inflammatory response via myeloperoxidase [59-62] that plays a significant role in asbestos-induced carcinogenesis [63]. Interestingly, immunoreactivities of 8nitroguanine, iNOS, and NF- $\kappa$ B significantly increased in the order of carcinogenic potential: crocidolite (blue asbestos) $>$ chrysotile (white asbestos) > control [42].

On the basis of our studies, various pathogenic factors induce inflammatory responses and the production of ROS and RNS from inflammatory and epithelial cells via iNOS expression, which is regulated by transcriptional factors including NF- $\kappa$ B, STAT, and HIF- $1 \alpha[2,3]$. Oxidative and nitrative stresses cause DNA damage, contributing to the accumulation of genetic alterations in tissues throughout the carcinogenic process. Particularly, 8-nitroguanine formation may participate in inflammation-related carcinogenesis as a common mechanism. Therefore, 8-nitroguanine could be used as a potential biomarker of inflammationrelated carcinogenesis. Importantly, experimental evidence has suggested that 8-nitroguanine can lead to mutations, preferentially $\mathrm{G}: \mathrm{C}$ to $\mathrm{T}: \mathrm{A}$ transversions $[46,64]$, in addition to 8 -oxodG $[9,65]$. Indeed, G:C to T:A transversions have been observed in vivo in the ras gene [66] and the $p 53$ tumor suppressor gene in lung and liver cancer $[67,68]$. We also revealed that 8-nitroguanine and 8-oxodG were apparently formed in adenocarcinoma caused by mutated K-ras, by using conditional transgenic mice with K-ras ${ }^{\text {val12 }}$ [69]. 8-Nitroguanine was colocalized with iNOS, NF- $\kappa$ B, IKK, MAPK, MEK, and mutated K-ras, suggesting that oncogenic K-ras causes additional DNA damage via signaling pathways involving these molecules. It is noteworthy that K-ras mutation mediates not only cell overproliferation but also the accumulation of mutagenic DNA lesions, leading to carcinogenesis. These findings imply that DNA damage mediated by ROS and RNS may participate in carcinogenesis via activation of protooncogenes and inactivation of tumor suppressor genes.

\section{Cancer Stem Cell Markers in Inflammation-Related Carcinogenesis}

The cancer stem cell concept is widely accepted as important for overcoming cancer. Several studies have revealed that cancer cells show accumulation of mutations, genetic instability, and epigenetic change suggesting that cancer is also a disease of genes [70]. The most important question is how to generate cancer stem cells. Recently, many studies have reported on the expressions of stemness cell markers in various kinds of cancer. Table 1 summarizes possible markers of cancer stem cells, especially related to each inflammatory causative agent. We reported that 8-nitroguanine was strongly formed at all of these cancer sites from animals and patients with infectious agents, inflammatory diseases, and exposure to asbestos. Importantly, we also detected colocalization of 8 -nitroguanine and stemness marker in infection-related carcinogenesis, as mentioned in the next section. On the basis of our recent studies, it is considered that chronic inflammation can increase mutagenic DNA lesions through ROS/RNS generation and can promote proliferation via stem cells activation for tissue regeneration. This idea is also supported by other papers about the association of cancer stem cells with infection and inflammation [71-74].

\section{DNA Damage and Mutant Stem Cells Induced by Schistosoma haematobium Infection}

Chronic infection with $\mathrm{SH}$ is associated with urinary bladder cancer [76]. Contact with contaminated freshwater is the major risk factor for infection. $\mathrm{SH}$-associated bladder cancer is a common malignancy, especially in the Middle East and Africa. It is believed that the parasite's eggs in the host 

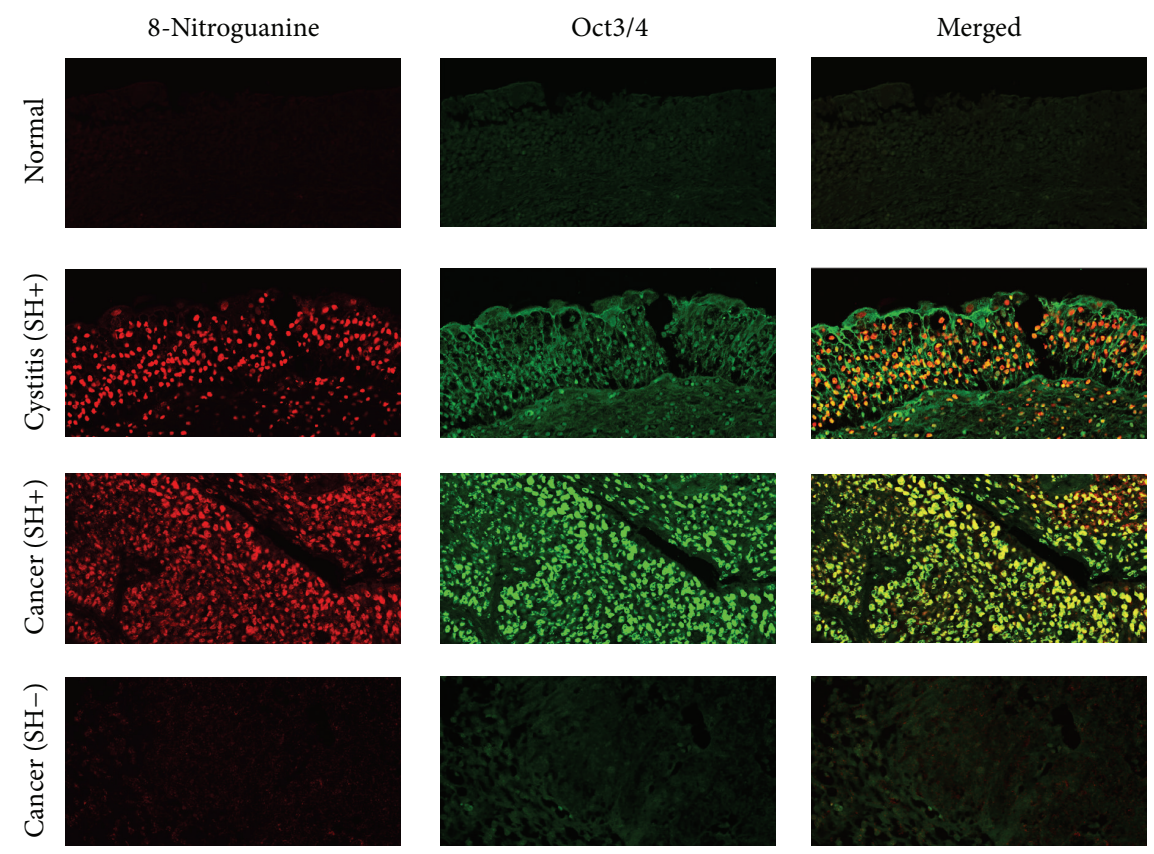

FIGURE 1: The formation of 8-nitroguanine (red) and the expression of Oct3/4 (green) were assessed by double immunofluorescence staining [10]. In the merged image, co-localization of 8 -nitroguanine and Oct $3 / 4$ is indicated in yellow. Original magnification in all pictures is $200 \mathrm{x}$ (SH: Schistosoma haematobium). Formalin-fixed and paraffin-embedded biopsy and surgical specimens were obtained from normal subjects and patients with $\mathrm{SH}$-induced cystitis and bladder cancer. Normal tissues and urinary bladder cancer tissues without SH infection were obtained from a commercial urinary bladder tissue array (Biomax.us, USA). Normal tissues with cystitis were excluded. SH-egg antigens in sera were detected by Sandwich ELISA assay [75]. This study was performed in accordance with the Ethical Guidelines for Epidemiological Research enacted by the Japanese government. Deparaffinized and antigen-retrieved sections were incubated first with 5\% skim milk, and then with a rabbit polyclonal anti-8-nitroguanine antibody $(2 \mu \mathrm{g} / \mathrm{mL}$, prepared as described previously [11] $)$ and mouse monoclonal antiOct3/4 antibody $(2 \mu \mathrm{g} / \mathrm{mL}$, Santa Cruz Biotechnology, CA, USA) overnight at room temperature. The sections were then incubated for $3 \mathrm{~h}$ with Alexa 594-labeled goat antibody against rabbit IgG and Alexa 488-labeled goat antibody against mouse IgG (each 1:400, Molecular Probes, Eugene, OR, USA).

bladder result in irritation, eventual fibrosis, and chronic cystitis, leading to carcinogenesis. To investigate whether oxidative and nitrative DNA damage participate in inflammationrelated carcinogenesis, we performed immunohistochemical analysis using bladder tissues obtained from cystitis and bladder cancer patients infected with SH. We demonstrated for the first time that 8-nitroguanine is formed in the tumors of bladder cancer patients with SH infection [10]. The formation of 8-nitroguanine and 8-oxodG was significantly higher in bladder cancer and cystitis tissues than in normal tissues. Oxidative DNA damage and $\mathrm{SH}$ infection were strongly correlated [10,77]. iNOS expression was co-localized with $\mathrm{NF}-\kappa \mathrm{B}$ in 8-nitroguanine-positive tumor cells from bladder cancer patients. NF- $\kappa$ B can be activated by TNF- $\alpha$, a major mediator of inflammation, which has been reported to increase in peripheral blood mononuclear cells stimulated by SH egg antigen [78]. It is reasonable to conclude that both 8-nitroguanine and 8-oxodG are formed by iNOS-mediated $\mathrm{NO}$ overproduction via NF- $\kappa \mathrm{B}$ activation, under $\mathrm{SH}$-caused chronic inflammation.

A stemness marker Oct3/4 is generally expressed in pluripotent embryonic stem and germ cells [79]. Expression of Oct3/4 is reportedly necessary for maintaining the selfrenewing, cancer stem-like, and chemoradioresistant properties of tumorigenic stem-like cell populations $[80,81]$ and is thus considered to play roles in the carcinogenesis process. Another stemness marker, CD44, has been identified as a cell surface marker associated with cancer stem cells in several types of tumors $[82,83]$, including urinary bladder cancer [84]. Expression of CD44v6, a splicing variant of $\mathrm{CD} 44$, is correlated with proliferation of poorly differentiated urothelial cells and the characteristic phenotype of tumorinitiating bladder cancer stem cells [85-87]. Our previous reports show that different risk factors induce different levels of expression of stemness markers in urinary bladder carcinoma. SH-induced urinary bladder cancer correlates with the expression of Oct3/4 [10], while urinary bladder cancer without the infection correlates with the expression of CD44v6 [11]. Moreover, 8-nitroguanine was formed in Oct3/4-positive stem cells in SH-associated cystitis and cancer tissues [10] as shown in Figure 1. Inflammation by $\mathrm{SH}$ infection may increase the number of mutant stem cells, in which iNOS-dependent DNA damage occurs via NF- $\kappa$ B activation, leading to tumor development. 

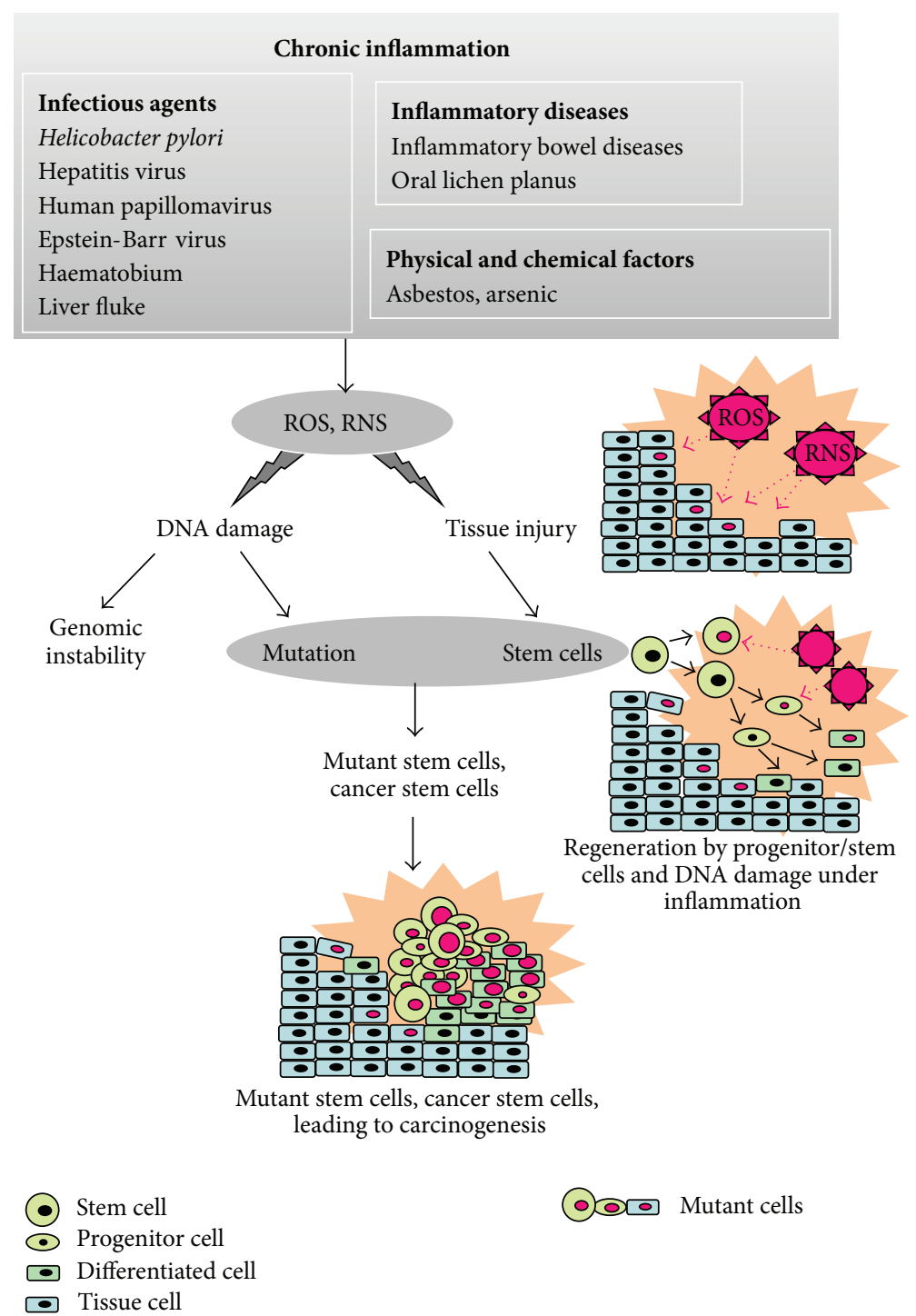

(O) Mutant cells

FIGURE 2: Postulated mechanism for generating cancer stem cells by inflammation.

\section{DNA Damage and Mutant Stem Cells Induced by Opisthorchis viverrini Infection}

Chronic infection with the liver fluke OV is associated with cholangiocarcinomas [58]. Infection with this parasite is repeatedly caused by eating raw fish containing the infective stage of the fluke. We have demonstrated that 8nitroguanine is formed in relation to inflammation-related carcinogenesis using an animal model [12-15]. 8-OxodG and 8-nitroguanine were formed in inflammatory cells and epithelium of bile ducts, and their formation increased in a manner dependent on infection times. The anthelmintic drug praziquantel dramatically diminished these DNA lesions and iNOS expression in OV-infected hamsters. Thus, repeated $\mathrm{OV}$-infection can induce the iNOS expression in bile ducts and subsequently cause nitrative and oxidative damage to nucleic acids, which may participate in cholangiocarcinoma.
In our study with patients, the formation of 8-oxodG and 8-nitroguanine occurred to a much greater extent in cancerous tissue than in noncancerous tissue in intrahepatic cholangiocarcinoma patients, indicating that these DNA lesions contribute to tumor progression [16]. Our proteomic study showed that carbonylation of serotransferrin and heat shock protein $70 \mathrm{kDa}$ protein 1 (HSP70.1) is significantly associated with poor prognoses [88]. Carbonylation of protein is an irreversible modification induced by oxidative stress. We have proposed that carbonylations of serotransferrin and HSP70.1 may induce oxidative stress by ironaccumulation and dysfunction of antioxidative property, leading to increased oxidative DNA damage and progression of cholangiocarcinoma.

Recently, we observed high expression and co-localization of hepatocyte marker and cholangiocyte marker in $\mathrm{OV}$-associated cholangiocarcinoma patients, suggesting the 
involvement of stem cells in cholangiocarcinoma development [17]. Cholangiocarcinoma tissues with positive stemness markers (CD133 or Oct3/4) showed significantly lower expression of antioxidant enzyme Mn-SOD and significantly higher levels of 8-oxodG, 8-nitroguanine, and DNA damage response protein $\gamma$-H2AX. Moreover, CD133- and Oct3/4positive cholangiocarcinoma patients had significant associations with tumor histology types, tumor stage, and poor prognoses. These findings suggest that CD133 and Oct3/4 in cholangiocarcinoma are highly associated with formation of DNA lesions, which may be involved in genetic instability and lead to tumor development with aggressive clinical features. In our study, proliferating cell nuclear antigen (PCNA) accumulated in the epithelium of bile ducts of hamsters after repeated OV infection, supporting the hypothesis that cell proliferation is promoted by inflammation-mediated DNA damage [14]. Inflammation by OV infection may increase the number of mutant stem cell, in which oxidative stresses, such as carbonylation of proteins and oxidative DNA damage, and cell proliferation are promoted, leading to progression of cholangiocarcinoma.

\section{Conclusions}

Nitrative and oxidative DNA lesions with mutagenic properties are formed in various types of inflammation-related cancer tissues. We have proposed a mechanism for the generation of cancer stem cells by inflammation in Figure 2. Chronic inflammation by infectious agents, inflammatory diseases, and other factors causes various types of damage to nucleic acids, proteins, tissue, and so on, via ROS/RNS generation. Tissue injury under chronic inflammation may activate progenitor/stem cells for regeneration. In these cells, ROS/RNS from inflammation can cause multiple mutations, which may generate mutant stem cells and cancer stem cells, leading to carcinogenesis. Indeed, 8-nitroguanine was formed in stemness marker-positive cells in parasite-associated cancer tissues. The mechanism for generation of cancer stem cells will be explained by our ongoing studies on the formation of 8-nitroguanine in stem-like cells of target tissues associated with other inflammation-related cancers.

\section{Conflict of Interests}

The authors declare that they have no conflict of interests.

\section{Acknowledgment}

This work was supported by a grant-in-aid from the Ministry of Education, Culture, Sports, Science and Technology of Japan.

\section{References}

[1] L. M. Coussens and Z. Werb, "Inflammation and cancer," Nature, vol. 420, no. 6917, pp. 860-867, 2002.

[2] S. Kawanishi and Y. Hiraku, "Oxidative and nitrative DNA damage as biomarker for carcinogenesis with special reference to inflammation," Antioxidants and Redox Signaling, vol. 8, no. 5-6, pp. 1047-1058, 2006.

[3] M. Murata, R. Thanan, N. Ma, and S. Kawanishi, "Role of nitrative and oxidative DNA damage in inflammation-related carcinogenesis," Journal of Biomedicine and Biotechnology, vol. 2012, Article ID 623019, 11 pages, 2012.

[4] IARC, "Chronic infections," in World Cancer Report, B. W. Stewart and P. Kleihues, Eds., pp. 128-135, IARC Press, Lyon, France, 2008.

[5] S. P. Hussain and C. C. Harris, "Inflammation and cancer: an ancient link with novel potentials," International Journal of Cancer, vol. 121, no. 11, pp. 2373-2380, 2007.

[6] A. J. Schetter, N. H. Heegaard, and C. C. Harris, "Inflammation and cancer: interweaving microRNA, free radical, cytokine and p53 pathways," Carcinogenesis, vol. 31, no. 1, Article ID bgp272, pp. 37-49, 2010.

[7] H. Ohshima, M. Tatemichi, and T. Sawa, "Chemical basis of inflammation-induced carcinogenesis," Archives of Biochemistry and Biophysics, vol. 417, no. 1, pp. 3-11, 2003.

[8] S. Kawanishi, Y. Hiraku, and S. Oikawa, "Mechanism of guanine-specific DNA damage by oxidative stress and its role in carcinogenesis and aging," Mutation Research, vol. 488, no. 1, pp. 65-76, 2001.

[9] S. D. Bruner, D. P. G. Norman, and G. L. Verdine, "Structural basis for recognition and repair of the endogenous mutagen 8oxoguanine in DNA," Nature, vol. 403, no. 6772, pp. 859-866, 2000.

[10] N. Ma, R. Thanan, H. Kobayashi et al., "Nitrative DNA damage and Oct3/4 expression in urinary bladder cancer with Schistosoma haematobium infection," Biochemical and Biophysical Research Communications, vol. 414, no. 2, pp. 344-349, 2011.

[11] R. Thanan, M. Murata, N. Ma et al., "Nuclear localization of COX-2 in relation to the expression of stemness markers in urinary bladder cancer," Mediators of Inflammation, vol. 2012, Article ID 165879, 8 pages, 2012.

[12] S. Pinlaor, Y. Hiraku, P. Yongvanit et al., "iNOS-dependent DNA damage via NF- $\kappa$ B expression in hamsters infected with Opisthorchis viverrini and its suppression by the antihelminthic drug praziquantel," International Journal of Cancer, vol. 119, no. 5, pp. 1067-1072, 2006.

[13] S. Pinlaor, Y. Hiraku, N. Ma et al., "Mechanism of NO-mediated oxidative and nitrative DNA damage in hamsters infected with Opisthorchis viverrini : a model of inflammation-mediated carcinogenesis," Nitric Oxide, vol. 11, no. 2, pp. 175-183, 2004.

[14] S. Pinlaor, N. Ma, Y. Hiraku et al., "Repeated infection with Opisthorchis viverrini induces accumulation of 8-nitroguanine and 8-oxo-7,8-dihydro- $2^{\prime}$-deoxyguanine in the bile duct of hamsters via inducible nitric oxide synthase," Carcinogenesis, vol. 25, no. 8, pp. 1535-1542, 2004.

[15] S. Pinlaor, P. Yongvanit, Y. Hiraku et al., "8-Nitroguanine formation in the liver of hamsters infected with Opisthorchis viverrini," Biochemical and Biophysical Research Communications, vol. 309, no. 3, pp. 567-571, 2003.

[16] S. Pinlaor, B. Sripa, N. Ma et al., "Nitrative and oxidative DNA damage in intrahepatic cholangiocarcinoma patients in relation to tumor invasion," World Journal of Gastroenterology, vol. 11, no. 30, pp. 4644-4649, 2005.

[17] R. Thanan, C. Pairojkul, S. Pinlaor et al., "Inflammationrelated DNA damage and expression of CD133 and Oct3/4 in cholangiocarcinoma patients with poor prognosis," Free Radical Biology \& Medicine, 2013. 
[18] S. Horiike, S. Kawanishi, M. Kaito et al., "Accumulation of 8nitroguanine in the liver of patients with chronic hepatitis C," Journal of Hepatology, vol. 43, no. 3, pp. 403-410, 2005.

[19] N. Ali, H. Allam, R. May et al., "Hepatitis C virus-induced cancer stem cell-like signatures in cell culture and murine tumor xenografts," Journal of Virology, vol. 85, no. 23, pp. 1229212303, 2011.

[20] K. Machida, H. Tsukamoto, H. Mkrtchyan et al., "Toll-like receptor 4 mediates synergism between alcohol and $\mathrm{HCV}$ in hepatic oncogenesis involving stem cell marker Nanog," Proceedings of the National Academy of Sciences of the United States of America, vol. 106, no. 5, pp. 1548-1553, 2009.

[21] Y. Hiraku, T. Tabata, N. Ma, M. Murata, X. Ding, and S. Kawanishi, "Nitrative and oxidative DNA damage in cervical intraepithelial neoplasia associated with human papilloma virus infection," Cancer Science, vol. 98, no. 7, pp. 964-972, 2007.

[22] S.-K. Kim, H.-S. Shim, K.-G. Lee, H.-J. An, K.-R. Lee, and N.-H. Cho, "Glassy cell carcinoma predominantly commits to a squamous lineage and is strongly associated with high-risk type human papillomavirus infection," International Journal of Gynecological Pathology, vol. 28, no. 4, pp. 389-395, 2009.

[23] S. Regauer and O. Reich, "CK17 and p16 expression patterns distinguish (atypical) immature squamous metaplasia from high-grade cervical intraepithelial neoplasia (CIN III)," Histopathology, vol. 50, no. 5, pp. 629-635, 2007.

[24] W.-K. Liu, Y.-L. Chu, F. Zhang et al., “The relationship between HPV16 and expression of CD44v6, $\mathrm{nm} 23 \mathrm{H} 1$ in esophageal squamous cell carcinoma," Archives of Virology, vol. 150, no. 5, pp. 991-1001, 2005.

[25] D. Liu, P. Zhou, L. Zhang et al., "HDAC1/DNMT3A-containing complex is associated with suppression of Oct4 in cervical cancer cells," Biochemistry, vol. 77, no. 8, pp. 934-940, 2012.

[26] N. Ma, M. Kawanishi, Y. Hiraku et al., "Reactive nitrogen species-dependent DNA damage in EBV-associated nasopharyngeal carcinoma: the relation to STAT3 activation and EGFR expression," International Journal of Cancer, vol. 122, no. 11, pp. 2517-2525, 2008.

[27] Q.-L. Kong, L.-J. Hu, J.-Y. Cao et al., "Epstein-barr virusencoded LMP2A induces an epithelial-mesenchymal transition and increases the number of side population stem-like cancer cells in nasopharyngeal carcinoma," PLoS Pathogens, vol. 6, no. 6, Article ID e1000940, 2010.

[28] A. Dutton, C. B. Woodman, M. B. Chukwuma et al., "Bmi-1 is induced by the Epstein-Barr virus oncogene LMP1 and regulates the expression of viral target genes in Hodgkin lymphoma cells," Blood, vol. 109, no. 6, pp. 2597-2603, 2007.

[29] N. Ma, Y. Adachi, Y. Hiraku et al., "Accumulation of 8nitroguanine in human gastric epithelium induced by Helicobacter pylori infection," Biochemical and Biophysical Research Communications, vol. 319, no. 2, pp. 506-510, 2004.

[30] M. Katsurahara, Y. Kobayashi, M. Iwasa et al., "Reactive nitrogen species mediate DNA damage in helicobacter pyloriinfected gastric mucosa," Helicobacter, vol. 14, no. 6, pp. 552$558,2009$.

[31] Y. Fujii, K. Yoshihashi, H. Suzuki et al., "CDX1 confers intestinal phenotype on gastric epithelial cells via induction of stemnessassociated reprogramming factors SALL4 and KLF5," Proceedings of the National Academy of Sciences of USA, vol. 109, no. 50, pp. 20584-10589, 2012.

[32] J. M. Noto, T. Khizanishvili, R. Chaturvedi et al., "Helicobacter pylori promotes the expression of Krüppel-like factor 5, a mediator of carcinogenesis, in vitro and in vivo," PLoS One, vol. 8, no. 1, Article ID e54344, 2013.

[33] T. Uehara, D. Ma, Y. Yao et al., "H. pylori infection is associated with DNA damage of Lgr5-positive epithelial stem cells in the stomach of patients with gastric cancer," Digestive Diseases and Sciences, vol. 58, no. 1, pp. 140-149, 2013.

[34] X. Ding, Y. Hiraku, N. Ma et al., "Inducible nitric oxide synthase-dependent DNA damage in mouse model of inflammatory bowel disease," Cancer Science, vol. 96, no. 3, pp. 157-163, 2005.

[35] P. Chaiyarit, N. Ma, Y. Hiraku et al., "Nitrative and oxidative DNA damage in oral lichen planus in relation to human oral carcinogenesis," Cancer Science, vol. 96, no. 9, pp. 553-559, 2005.

[36] L. Ma, H. Wang, H. Yao, L. Zhu, W. Liu, and Z. Zhou, "Bmil expression in oral lichen planus and the risk of progression to oral squamous cell carcinoma," Annals of Diagnostic Pathology, vol. 17, no. 4, pp. 327-330, 2013.

[37] A. Bose, M. T. Teh, I. L. Hutchison, H. Wan, I. M. Leigh, and A. Waseem, "Two mechanisms regulate keratin K15 expression in keratinocytes: role of PKC/AP-1 and FOXM1 mediated signalling," PLoS One, vol. 7, no. 6, Article ID e38599, 2012.

[38] R. Thanan, N. Ma, K. Iijima et al., "Proton pump inhibitors suppress iNOS-dependent DNA damage in Barrett's esophagus by increasing Mn-SOD expression," Biochemical and Biophysical Research Communications, vol. 421, no. 2, pp. 280-285, 2012.

[39] J. Mendelson, S. Song, Y. Li et al., "Dysfunctional transforming growth factor- $\beta$ signaling with constitutively active notch signaling in Barrett's esophageal adenocarcinoma," Cancer, vol. 117, no. 16, pp. 3691-3702, 2011.

[40] J. Ahmad, K. Arthur, P. Maxwell et al., "Re: grotenhuis et al. Barrett's oesophageal adenocarcinoma encompasses tumourinitiating cells that do not express common cancer stem cell markers. J Pathol 2010; 221: 379-389," Journal of Pathology, vol. 224, no. 1, pp. 143-145, 2011.

[41] Y. V. Bobryshev, A. K. Freeman, N. K. Botelho, D. Tran, A. J. M. Levert-Mignon, and R. V. N. Lord, "Expression of the putative stem cell marker Musashi-1 in Barrett's esophagus and esophageal adenocarcinoma," Diseases of the Esophagus, vol. 23, no. 7, pp. 580-589, 2010.

[42] Y. Hiraku, S. Kawanishi, T. Ichinose, and M. Murata, "The role of iNOS-mediated DNA damage in infection- and asbestosinduced carcinogenesis," Annals of the New York Academy of Sciences, vol. 1203, pp. 15-22, 2010.

[43] D. Fukumura, S. Kashiwagi, and R. K. Jain, "The role of nitric oxide in tumour progression," Nature Reviews Cancer, vol. 6, no. 7, pp. 521-534, 2006.

[44] P. K. Lala and C. Chakraborty, "Role of nitric oxide in carcinogenesis and tumour progression," Lancet Oncology, vol. 2, no. 3, pp. 149-156, 2001.

[45] S. Wang, Z. Liu, L. Wang, and X. Zhang, "NF- $\kappa$ B signaling pathway, inflammation and colorectal cancer," Chinese Journal of Cellular and Molecular Immunology, vol. 6, no. 5, pp. 327-334, 2009.

[46] V. Yermilov, J. Rubio, M. Becchi, M. D. Friesen, B. Pignatelli, and H. Ohshima, "Formation of 8-nitroguanine by the reaction of guanine with peroxynitrite in vitro," Carcinogenesis, vol. 16, no. 9, pp. 2045-2050, 1995.

[47] B. Halliwell, "Oxygen and nitrogen are pro-carcinogens. Damage to DNA by reactive oxygen, chlorine and nitrogen species: measurement, mechanism and the effects of nutrition," Mutation Research, vol. 443, no. 1-2, pp. 37-52, 1999. 
[48] R. S. Sodum and E. S. Fiala, "Analysis of peroxynitrite reactions with guanine, xanthine, and adenine nucleosides by highpressure liquid chromatography with electrochemical detection: C8-nitration and -oxidation," Chemical Research in Toxicology, vol. 14, no. 4, pp. 438-450, 2001.

[49] T. Akaike, S. Fujii, A. Kato et al., "Viral mutation accelerated by nitric oxide production during infection in vivo," The FASEB Journal, vol. 14, no. 10, pp. 1447-1454, 2000.

[50] N. Ma, M. Murata, S. Ohnishi, R. Thanan, Y. Hiraku, and S. Kawanishi, "8-Nitroguanine, a potential biomarker to evaluate the risk of inflammation-related carcinogenesis," in Biomarker, T. K. Kahn, Ed., chapter 10, pp. 201-224, InTech, Rijeka, Croatia, 2012.

[51] V. Yermilov, J. Rubio, and H. Ohshima, "Formation of 8nitroguanine in DNA treated with peroxynitrite in vitro and its rapid removal from DNA by depurination," The FEBS Letters, vol. 376, no. 3, pp. 207-210, 1995.

[52] L. A. Loeb and B. D. Preston, "Mutagenesis by apurinic/apyrimidinic sites," Annual Review of Genetics, vol. 20, pp. 201-230, 1986.

[53] S. Boiteux and M. Guillet, "Abasic sites in DNA: repair and biological consequences in Saccharomyces cerevisiae," DNA Repair, vol. 3, no. 1, pp. 1-12, 2004.

[54] J. E. Sale, A. R. Lehmann, and R. Woodgate, "Y-family DNA polymerases and their role in tolerance of cellular DNA damage," Nature Reviews Molecular Cell Biology, vol. 13, no. 3, pp. 141-152, 2012.

[55] X. Wu, K. Takenaka, E. Sonoda et al., "Critical roles for polymerase $\zeta$ in cellular tolerance to nitric oxide-induced DNA damage," Cancer Research, vol. 66, no. 2, pp. 748-754, 2006.

[56] N. Suzuki, M. Yasui, N. E. Geacintov, V. Shafirovich, and S. Shibutani, "Miscoding events during DNA synthesis past the nitration-damaged base 8-nitroguanine," Biochemistry, vol. 44, no. 25, pp. 9238-9245, 2005.

[57] M. Y. Kim, M. Dong, P. C. Dedon, and G. N. Wogan, "Effects of peroxynitrite dose and dose rate on DNA damage and mutation in the supF shuttle vector," Chemical Research in Toxicology, vol. 18, no. 1, pp. 76-86, 2005.

[58] IARC, "Opisthorchis viverrini and Clonorchis sinensis," in $A$ Review of Human CarcInogens: Biological Agents, vol. 100B of IARC Monographs on the Evaluation of Carcinogenic Risks to Humans, pp. 347-376, IARC Press, Lyon, France, 2012.

[59] J. P. Eiserich, M. Hristova, C. E. Cross et al., "Formation of nitric oxide-derived inflammatory oxidants by myeloperoxidase in neutrophils," Nature, vol. 391, no. 6665, pp. 393-397, 1998.

[60] J. P. Gaut, J. Byun, H. D. Tran et al., "Myeloperoxidase produces nitrating oxidants in vivo," Journal of Clinical Investigation, vol. 109, no. 10, pp. 1311-1319, 2002.

[61] S. Tanaka, N. Choe, D. R. Hemenway, S. Zhu, S. Matalon, and E. Kagan, "Asbestos inhalation induces reactive nitrogen species and nitrotyrosine formation in the lungs and pleura of the rat," Journal of Clinical Investigation, vol. 102, no. 2, pp. 445-454, 1998.

[62] A. Van Der Vliet, J. P. Eiserich, M. K. Shigenaga, and C. E. Cross, "Reactive nitrogen species and tyrosine nitration in the respiratory tract: epiphenomena or a pathobiologic mechanism of disease?" American Journal of Respiratory and Critical Care Medicine, vol. 160, no. 1, pp. 1-9, 1999.

[63] A. Haegens, A. Van Der Vliet, K. J. Butnor et al., "Asbestosinduced lung inflammation and epithelial cell proliferation are altered in myeloperoxidase-null mice," Cancer Research, vol. 65, no. 21, pp. 9670-9677, 2005.
[64] N. Suzuki, M. Yasui, N. E. Geacintov, V. Shafirovich, and S. Shibutani, "Miscoding events during DNA synthesis past the nitration-damaged base 8-nitroguanine," Biochemistry, vol. 44, no. 25, pp. 9238-9245, 2005.

[65] S. Shibutani, M. Takeshita, and A. P. Grollman, "Insertion of specific bases during DNA synthesis past the oxidationdamaged base 8-oxodG," Nature, vol. 349, no. 6308, pp. 431-434, 1991.

[66] J. L. Bos, "The ras gene family and human carcinogenesis," Mutation Research, vol. 195, no. 3, pp. 255-271, 1988.

[67] S. P. Hussain, L. J. Hofseth, and C. C. Harris, "Radical causes of cancer," Nature Reviews Cancer, vol. 3, no. 4, pp. 276-285, 2003.

[68] T. Takahashi, M. M. Nau, I. Chiba et al., "p53: a frequent target for genetic abnormalities in lung cancer," Science, vol. 246, no. 4929, pp. 491-494, 1989.

[69] S. Ohnishi, H. Saito, N. Suzuki et al., "Nitrative and oxidative DNA damage caused by K-ras mutation in mice," Biochemical and Biophysical Research Communications, vol. 413, no. 2, pp. 236-240, 2011.

[70] M. Shipitsin and K. Polyak, "The cancer stem cell hypothesis: in search of definitions, markers, and relevance," Laboratory Investigation, vol. 88, no. 5, pp. 459-463, 2008.

[71] S. Sell, "Infection, stem cells and cancer signals," Current Pharmaceutical Biotechnology, vol. 12, no. 2, pp. 182-188, 2011.

[72] S. Reuter, S. C. Gupta, M. M. Chaturvedi, and B. B. Aggarwal, "Oxidative stress, inflammation, and cancer: how are they linked?” Free Radical Biology and Medicine, vol. 49, no. 11, pp. 1603-1616, 2010.

[73] Y. Jing, Z. Han, Y. Liu et al., "Mesenchymal stem cells in inflammation microenvironment accelerates hepatocellular carcinoma metastasis by inducing epithelial-mesenchymal transition," PLoS One, vol. 7, no. 8, Article ID e43272, 2012.

[74] N. J. Maitland and A. T. Collins, "Inflammation as the primary aetiological agent of human prostate cancer: a stem cell connection?" Journal of Cellular Biochemistry, vol. 105, no. 4, pp. 931-939, 2008.

[75] Z. A. Shaker, M. A. Kaddah, S. B. Hanallah, and M. I. ElKhodary, "Production of monoclonal antibodies against target schistosomal antigen secreted in the urine of schistosoma mansoni-infected patients," International Journal for Parasitology, vol. 28, no. 12, pp. 1893-1901, 1998.

[76] IARC, "Schistosoma haematobium," in A Review of Human CarcInogens: Biological Agents, vol. 100B of IARC Monographs on the Evaluation of Carcinogenic Risks to Humans, pp. 371-384, IARC Press, Lyon, France, 2012.

[77] E. I. Salim, K. Morimura, A. Menesi, M. El-Lity, S. Fukushima, and $\mathrm{H}$. Wanibuchi, "Elevated oxidative stress and DNA damage and repair levels in urinary bladder carcinomas associated with schistosomiasis," International Journal of Cancer, vol. 123, no. 3 , pp. 601-608, 2008.

[78] A. N. Wamachi, J. S. Mayadev, P. L. Mungai et al., "Increased ratio of tumor necrosis factor- $\alpha$ to interleukin-10 production is associated with Schistosoma haematobium-induced urinarytract morbidity," Journal of Infectious Diseases, vol. 190, no. 11, pp. 2020-2030, 2004.

[79] L. H. Looijenga, H. Stoop, H. P. De Leeuw et al., "POU5F1 (OCT3/4) identifies cells with pluripotent potential in human germ cell tumors," Cancer Research, vol. 63, no. 9, pp. 22442250, 2003.

[80] Y.-C. Chen, H.-S. Hsu, Y.-W. Chen et al., "Oct-4 expression maintained cancer stem-like properties in lung cancer-derived 
CD133-positive cells," PLoS One, vol. 3, no. 7, Article ID e2637, 2008.

[81] D. Ponti, A. Costa, N. Zaffaroni et al., "Isolation and in vitro propagation of tumorigenic breast cancer cells with stem/progenitor cell properties," Cancer Research, vol. 65, no. 13, pp. 5506-5511, 2005.

[82] Y. Matsumura and D. Tarin, "Significance of CD44 gene products for cancer diagnosis and disease evaluation," Lancet, vol. 340, no. 8827, pp. 1053-1058, 1992.

[83] S. Saito, H. Okabe, M. Watanabe et al., "CD44v6 expression is related to mesenchymal phenotype and poor prognosis in patients with colorectal cancer," Oncology Reports, vol. 29, no. 4, pp. 1570-1578, 2013.

[84] E. M. Peek, D. R. Li, H. Zhang et al., "Stromal modulation of bladder cancer-initiating cells in a subcutaneous tumor model," American Journal of Cancer Research, vol. 2, no. 6, pp. 745-751, 2012.

[85] J. Kuncová, M. Urban, and V. Mandys, "Expression of CD44s and CD44v6 in transitional cell carcinomas of the urinary bladder: comparison with tumour grade, proliferative activity and p53 immunoreactivity of tumour cells," APMIS, vol. 115, no. 11, pp. 1194-1205, 2007.

[86] M. Sugiyama, A. Woodman, T. Sugino et al., "Non-invasive detection of bladder cancer by identification of abnormal CD 44 proteins in exfoliated cancer cells in urine," Journal of Clinical Molecular Pathology, vol. 48, no. 3, pp. M142-M147, 1995.

[87] Y. M. Yang and J. W. Chang, "Bladder cancer initiating cells (BCICs) are among $\mathrm{EMA}^{-} \mathrm{CD} 44 \mathrm{v} 6{ }^{+}$subset: novel methods for isolating undetermined cancer stem (initiating) cells," Cancer Investigation, vol. 26, no. 7, pp. 725-733, 2008.

[88] R. Thanan, S. Oikawa, P. Yongvanit et al., "Inflammationinduced protein carbonylation contributes to poor prognosis for cholangiocarcinoma," Free Radical Biology and Medicine, vol. 52, no. 8, pp. 1465-1472, 2012. 


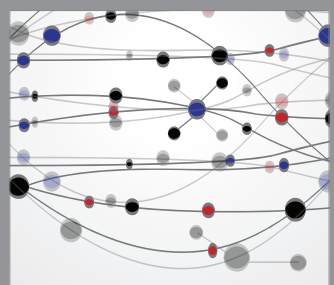

The Scientific World Journal
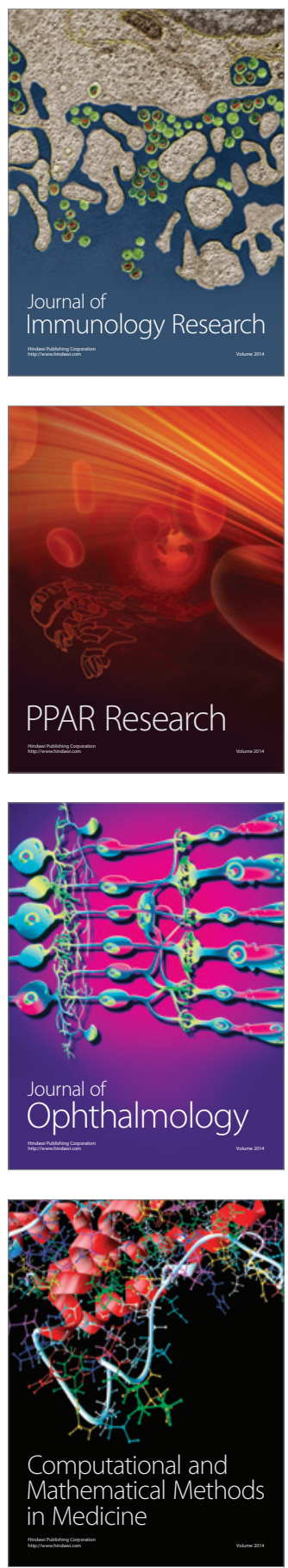

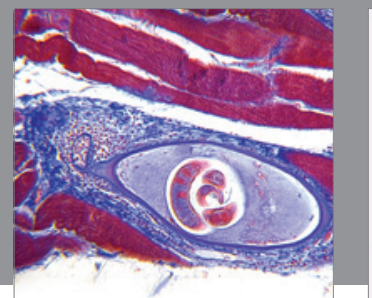

Gastroenterology

Research and Practice
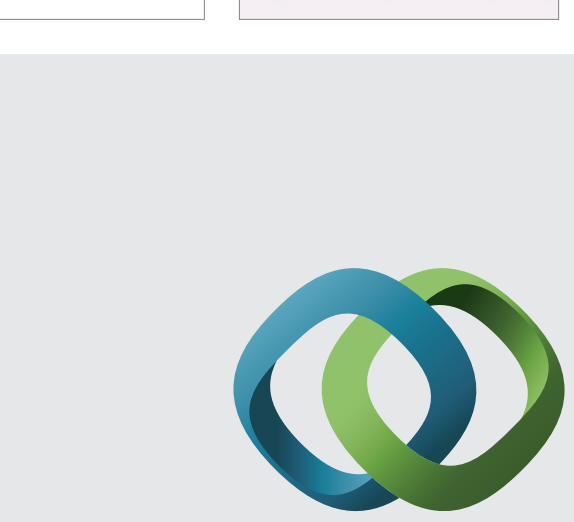

\section{Hindawi}

Submit your manuscripts at

http://www.hindawi.com
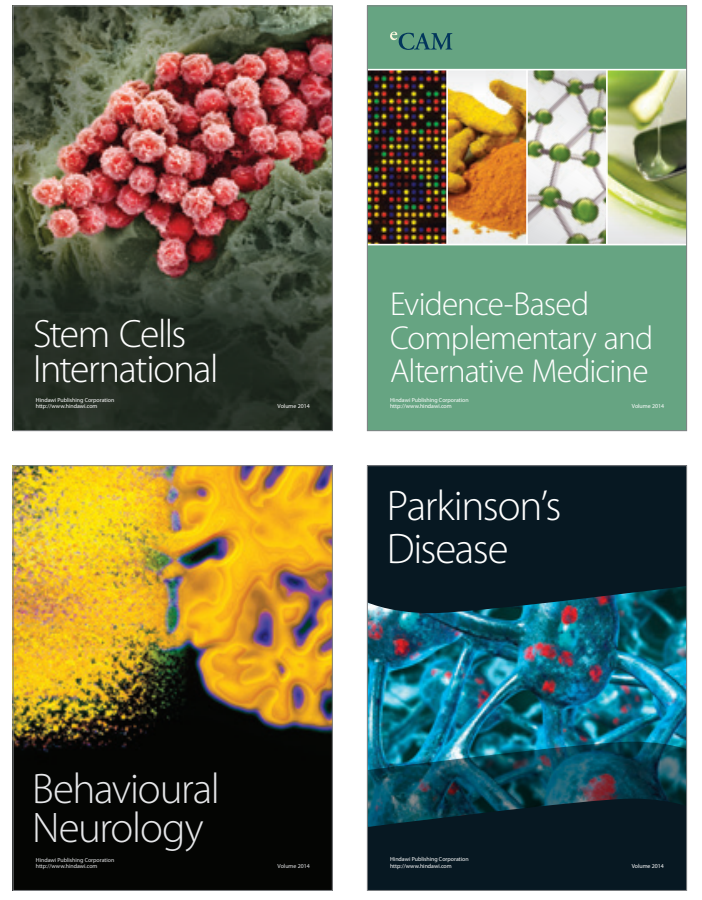
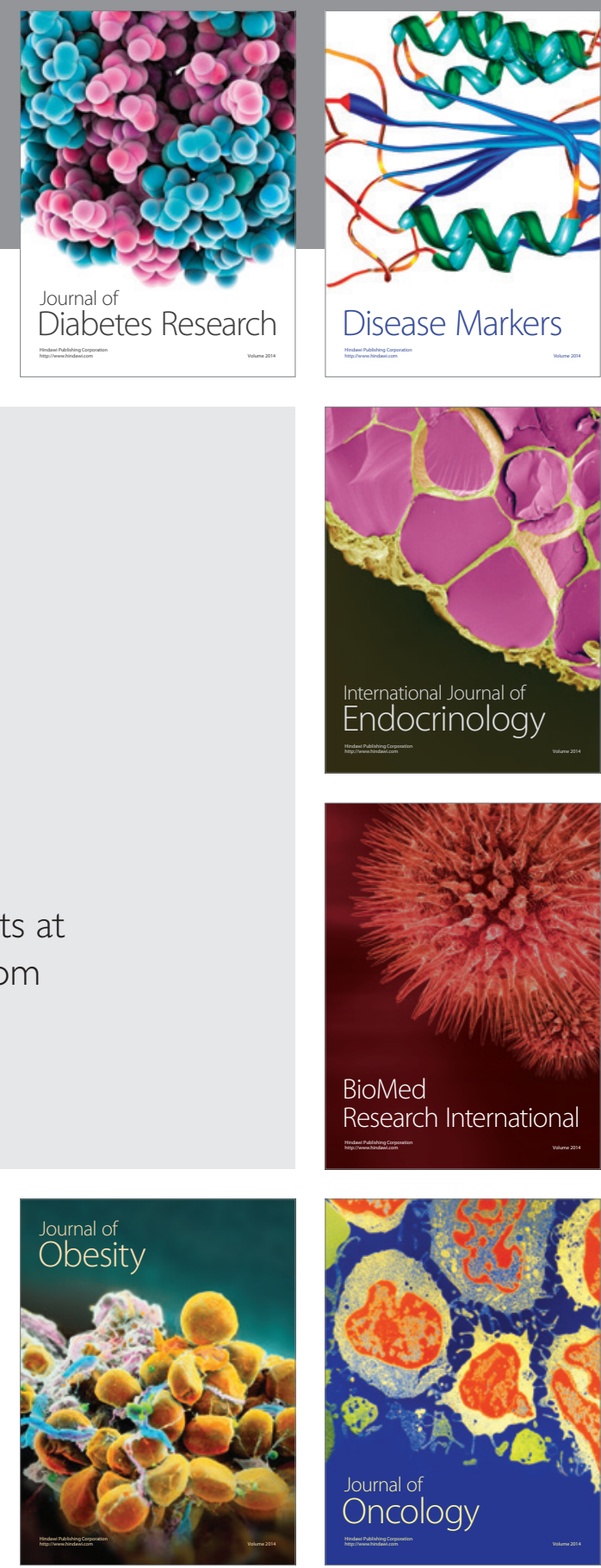

Disease Markers
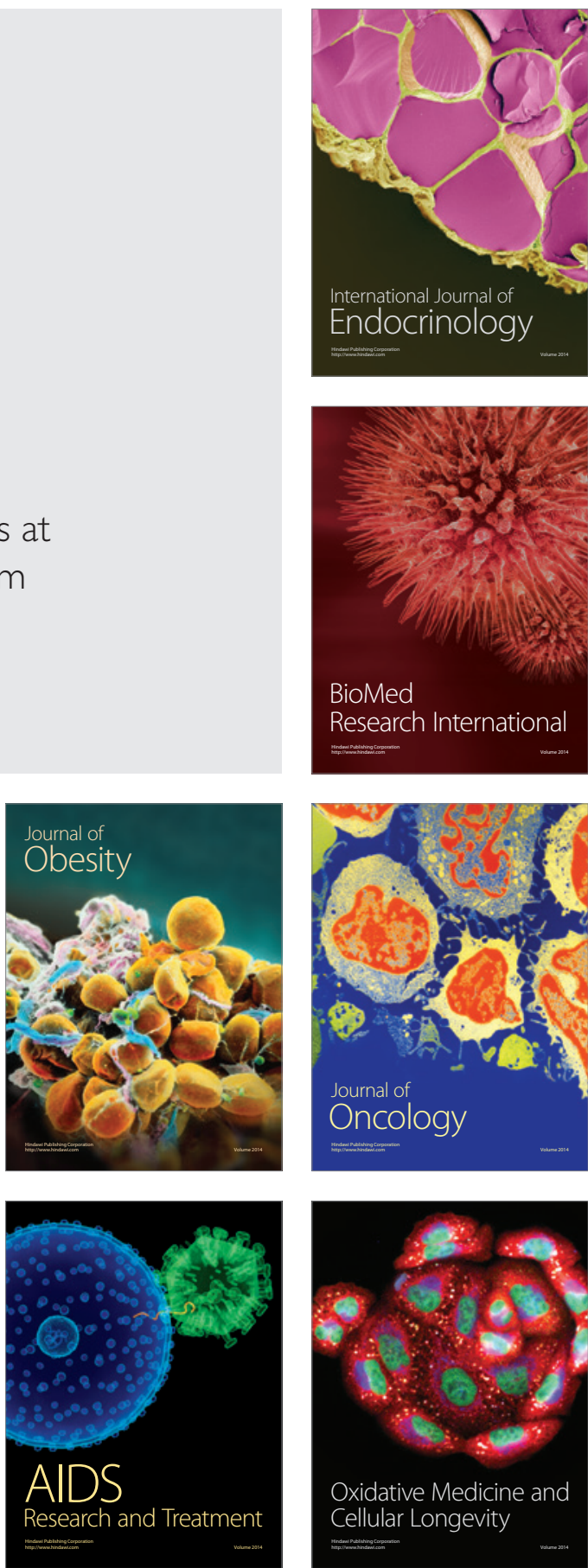